\title{
Untethering the Queue based on Multi Channel Access (MCA) Technology at Hospital Radiology Section
}

\author{
Dharma Dyatmika ${ }^{1) *}$, Oka Sudana ${ }^{2)}$, Gusti Agung A. Putri ${ }^{3)}$ \\ 1)2)3) Information Technology of Udayana University, Indonesia \\ Jl. Raya Kampus UNUD, Kampus Bukit Jimbaran, Kuta Selatan, Jimbaran, Kec. Kuta Selatan., Kabupaten Badung, Bali \\ ${ }^{1)}$ kadekdharma11@gmail.com, ${ }^{2)}$ agungokas@unud.ac.id, ${ }^{3)}$ agung.ayuputri@unud.ac.id
}

Article history:

Received 30 March 2019

Revised 30 August 2019

Accepted 17 September 2019

Available online 28 October 2019

Keywords:

First Come First Serve, Multi Channel Access, SMS, Telegram, Untethering the Queue

\begin{abstract}
Background: Information technology is developing rapidly over time, but there are many companies do not make use of it to support their operational activities. One example is the queue system in the Radiology Section of Sanglah Hospital, which operates the conventional queue system.

Objective: The problem occurs in this queue system is inefficient waiting time because the patients must come early and wait in line in the hospital waiting rooms. Many patients thereafter decide going home first or doing other activities. Another problem is it triggers double costs of transportation. The purpose of this study is to improve patients comfort while waiting in queue by applying untethering the queue. Untethering the queue is a service that allows people to be in a queue even though they are not in the waiting room.

Methods: The system applies the FCFS (First Come First Serve) algorithm to manage patients' queue and integrates this queue system with Telegram and SMS gateway. It makes patients easier to take queue numbers and receive notification of health service time from the Radiology Section of Sanglah Hospital.

Result: As a result of this study is an untethering the queue application which is web-based queue system integrated to Telegram and SMS gateway. The daily queue services in the Radiology Section of Hospital can be improved through this application.

Conclusion: Patients can only come to the hospital when the queue numbers obtained nearly the health service time so that it leads to time efficient and comfort while waiting in queue.
\end{abstract}

\section{INTRODUCTION}

Registration in the Hospital Radiology Section of Sanglah Hospital still makes use of a conventional system. This raises problem inefficient of waiting time because patients have to arrive early and queue in long lines at the hospital waiting room, which sometimes leads patient left the queue, going home first or doing another activities. It is also doubles the costs of transportation when they return to the hospital [1]. This study proposed implementing a system namely "untethering the queue" to solve this problem. Untethering the queue allows patients to be in the queue even though they are not in the hospital waiting room physically. The system manages the queue of patients by allowed patients doing other activities while waiting in line virtually and coming to the hospital waiting room when they have approached their turn number. This research purposes to built untethering the queue application which designed to manage virtual in line queue number. Patient can hold on their queue number anywhere without losing the in line queue.

Similar to previous studies that only can be accessed through a website, patient who do not have supporting devices such as smart phones or laptops cannot access the queue system [2]. Untethering the queue is developed by built a web-based queue system with a First Come First Serve (FCFS) queue model that is integrated with MultiChannel Access (MCA) technology to facilitate patient's accesses the queue from several channels. The FCFS queue model is a queue method where patient who gets a queue number earlier will be served first. Then, Patient who has finished their health services will be replaced by other patient who holds the next queue number. This sequence continues until the last queue sequence.

\footnotetext{
${ }^{*}$ Corresponding author
} 
Untethering the Queue application is designed to provide convenience for registered patient to ask number of queue via Telegram or an SMS by using their smart phone. It application will send notification message to patients if the nearest queue number gets their turn. Application also sends a reminder so that patient should come soon to the Radiology Section of Sanglah Hospital, when their queue number approaches their turn via SMS or Telegram. Therefore, patient no needs physically in the queue line at the hospital waiting room.

Previous research has built a similar queue system, such as research conducted by Manoon Ngorsed [2], this system allows people to monitor their queue status from the website service application. This system is designed to offer options for people who are waiting for services, they can go any where when they are in line. This lack of a queue system that can only be accessed through a website, people who do not have supporting devices such as smart phones or laptops cannot access. Another similar research that developed about the queue system that allows retrieving queue numbers using website-based computerization, so customers do not need to go to the cashier to get a queue number [3]. They just need to access through the website page. The disadvantages of this system are also only accessible through the website, so that people who do not have a supporting device cannot access. Previous study also explore mobile platform for developing te queue system [4]. Application development applies a hybrid mobile web framework that can be used for multiplatform development. Using of this system allows patients to register through the application on a smart phone. This application only focuses on mobile applications so that to register patients must have a smart phone, where not everyone has a smartphone. Other research added SMS Gateway and Telegram application to anticipate patients who have not used Android [5,6]. The use of this system allows patients to register via SMS, with the patient no longer needed to come to the clinic just to get a queue number. The patient can register anywhere. The application only focuses on the SMS gateway, which means that registration charges phone credit. In the internet era like today, rarely people use phone credits because they already use data packages. Other studies related to the queue system develop in web-based queue platform[7], its adding SMS gateways and Telegram applications to make it easier for prospective patients in the registration and notification process without having to monitor the website and predict if he queue number is near.

Based on previous studies and interviews with patients in the Radiology services of Sanglah Hospital, a webbased online queue system was built, which is integrated with the SMS gateway and Telegram technologies to facilitate the registration process, and provide notifications to patients who have registered.

\section{LITERATURE REVIEW}

\section{A. Queue Theory}

The queue system is a set of customers, servants, and a rule that regulates customer service. The number of servants that are too much will require a large amount of costs; on the contrary if the number of servants is less then there will be a queue for a long time which will also incur costs, either in the form of social costs, loss of subscriptions, or worker unemployment. The main purpose of the queue theory is to achieve a balance between the cost of service and the costs caused by the existence of waiting times [8].

The queue process is generally grouped into four basic structural models according to the characteristics and services, that is Single Channel-Single Phase, One Channel Many Stages (Single Channel-Multi Phase), Many Single-Stage Channels (Multi Channel-Single Phase), Many Multi-Stage Multi-Channel [9].

First Come First Serve (FCFS) queue discipline is the queue discipline used in this study. This queue discipline was adjusted to the service workflow algorithm in the Radiology Section of Sanglah Hospital. The basic principle of FCFS queues is that the first packet that arrives at the system is the first packet sent. Exceptions occur if a packet arrives and the queue is full, then the router will ignore the packet under any circumstances [10].

\section{B. Telegram API}

Telegram Application Programming Interface (API) is a set of specific rules and specifications that can access, utilize the services and resources provided by Telegram for other software that implements the API [11]. The Telegram API can be used to build bots that can be used to share information. Information can be obtained by using Telegram Bot by sending messages in the form of commands. The main purpose of using a bot is to increase user comfort. The use of Telegram Bot has several benefits because it can save time, storage, and use of internet data, because that information can be obtained from bots without opening a website [12].

The Telegram Bot API can be used in the system as a notification media. It is used as a gateway for accessing some related data[13]. The API defines how programmers utilize certain features of an application. APIs are available for windowing, file system, database systems and network systems [14]. 


\section{SMS Gateway}

SMS gateway is the gateway to send information in the form of SMS. SMS can be automatically sent to hundreds of numbers quickly which are directly connected to the database of mobile numbers without inputting each number [15]. SMS gateway that has two-way nature, makes this type of SMS very suitable to be used as an SMS centre for certain organizations or institutions[16].

SMS gateway is a two-way SMS with the same uniqueness of the usual SMS rates provided by operators. SMS gateways have two directional characteristics and are very suitable for use as SMS centre used by organizations or institutions. The SMS centre consists of two types in terms of its development, namely using a protocol connected to the internet network, one of the protocols used is SMPP (Short Message Peer to Peer Protocol) and SMS server services that are directly connected to the GSM network [17].

\section{Website}

Website is a set of pages that contain digital information in the form of text, images and animations that are provided through an internet connection so that it can be accessed from all over the world. It consists of several elements, namely domain names, web hosting, programming languages, web design, and file transfer protocol. The request for access made by the user is responded to by the web application, which is then displayed through the display on the web browser used [18].

Website services are used as facilities provided by website sites to provide services in the form of information to other systems, so that other systems can interact with the system through services (services) provided by systems that provide website services [19].

\section{METHODS}

\section{A. System Architecture}

The system architecture of the queue system is explained through the following picture:

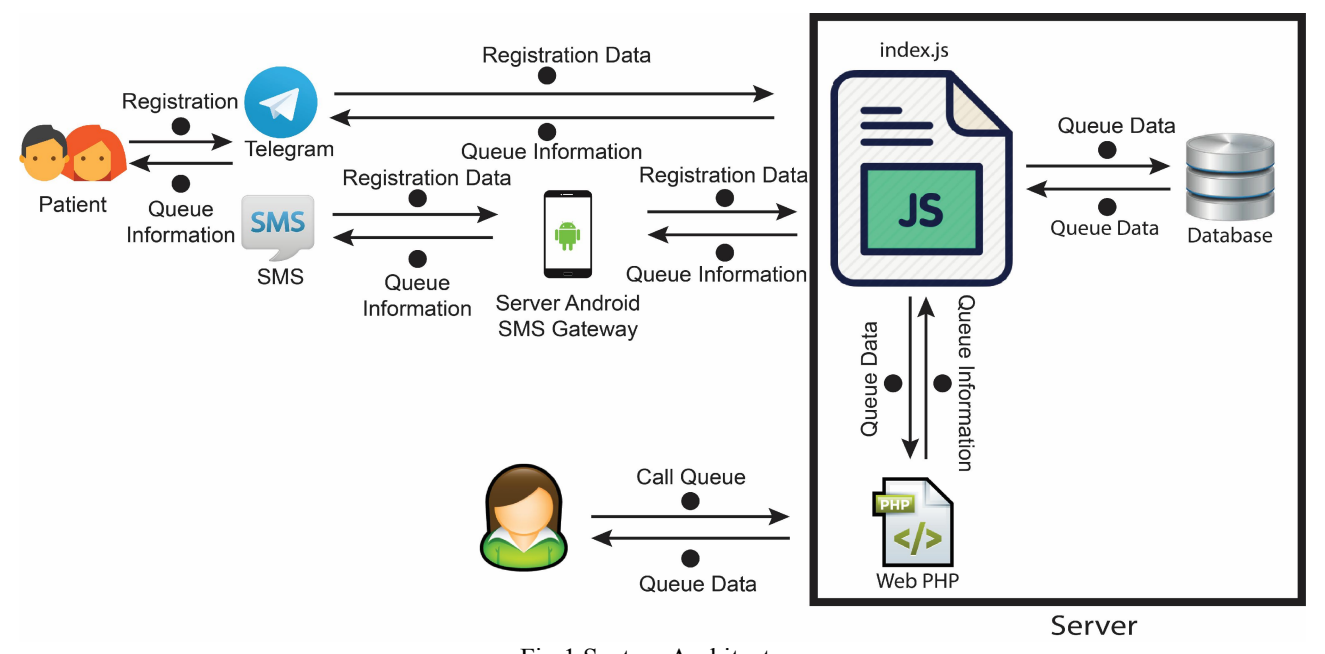

Fig.1 System Architecture

Fig. 1 shows architecture of untethering the queue system. Registered patient of Sanglah Hospital can sign up to the untethering the queue either through SMS or Telegram. If they register through SMS, then SMS will enter first through the Android SMS gateway server and then forwarded into the server. When patient registered through Telegram, then the registration data will be sent directly to the server. The server runs a couple of processes like Bot API, website, and database. The server will perform tasks such as data classification which will be sent to patient, such as registration, cancellation, arrival, or queue data requests. The queue data will be displayed on the website to be accessed by administrators or employees. When a certain queue number has received its service, then the administrator will update the status, where the update triggers the server to call or send a notification to the next queue number, the second next, and the third next, and so on. The notification message will be sent through Telegram if the patient registered through Telegram, and through SMS if the patient through SMS. 


\section{B. FCFS Algorithm Analysis in Registration Queuing System}

Services for patients will be carried out sequentially according to the queue number of each patient. Flowchart for the system queue first come first serve (FCFS) can be seen in Fig. 2.

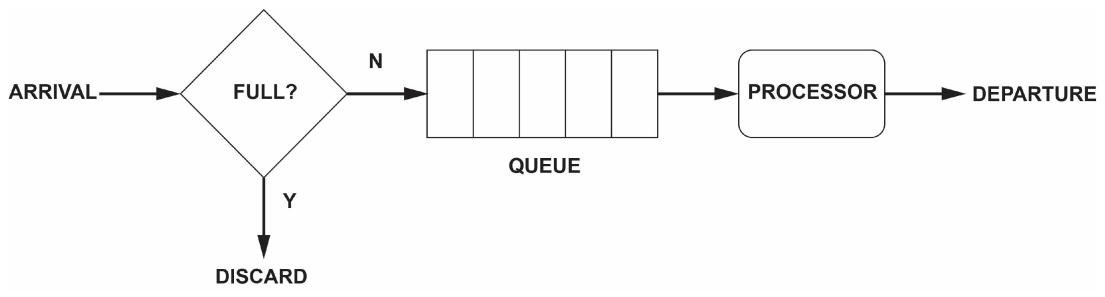

Fig. 2 Flowchart of Queue System

Fig. 2 illustrates flowchart of a first come first service (FCFS) queue system. Patients who sign up will be checked first by the system, whether the queue number is available or already full. If the queue is full then patient cannot enter the line. However, if the queue is available, then the patient will receive the queue number and enter the line. Pseudo code of FCFS queue system can be seen in Fig. 3 as follows.

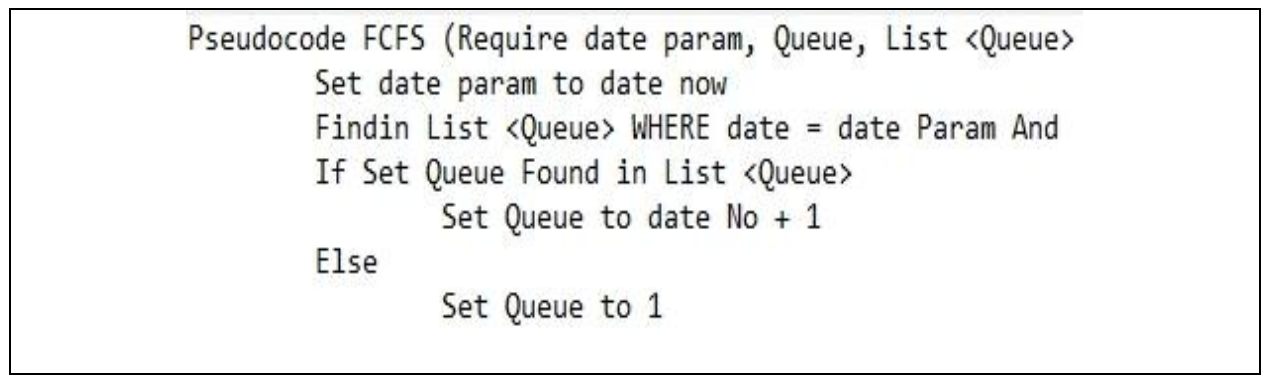

Fig. 3 Pseudo code of FCFS Queue System

Fig. 3 describes a line of pseudo code for the FCFS queue system. The system calls the incoming queue that day, and check the last queue number also in that day to generate a queue number. If there is no line, the queue number will start from one, but if there is a previous queue number then one will be added.

\section{System Evaluation}

Testing of the system is done at laboratory by 30 users as patients and 1 user as administrator. Testing of the system used the black box method which is focuses on input, functionality and output for all of the queuing process. The test can later give conclusions to what extent the application is able to solve existing problems.

\section{RESULTS}

\section{A. System Overview}

The untethering the queue system is divided into 5 parts, namely login, master, queue, report, Telegram bot, and SMS bot. The queue system at the Radiology Section of Sanglah Hospital is web-based and integrated with Telegram and SMS gateway having admin access as the queue system manager. Login to admin system uses input data of a username and password. If the input data with the status of the admin is correct, user will successfully enter the admin dashboard page. Admin dashboard page contains information about the features available in the queue application, namely the Dashboard, Master, Queue, and Report menus.

The Dashboard page can display the number of patients waiting in the queue, the number of patients who cancelled the arrival, and the number of patients who have received the services. The Master page is an interface that displays features for accessing users, types of services, patients, and rooms. Admin can manipulate data such as adding, editing, and deleting data in accordance with the features of the master page.

The Reports page is an interface that displays features for accessing queue reports. The queue data report contains the queue number, chat id field, chat type, medical record number, name, phone number, type of service, date, status. 
Website list is a page that displays a feature for admin to register if a patient registers by coming directly to the Radiology Section of Sanglah Hospital. Registration is done by the admin entering the patient's medical record number, and then the system will display the patient's data according to the medical record number input. The patient data form page contains the medical record number, gender, name, email, telephone number, cellular phone number, address, and type of service the patient wants. Patients can also register through the Telegram application and SMS gateway. Patients who register through the Telegram and SMS application can send a message "/ daftar: [medical record number]\# [service type code]", patients will receive a queue data reply in the form of a queue number, medical record number, name of service type, telephone, and queue number information in front. Patients will get a notification to come to the Sanglah Hospital Radiology Section and an estimated turn time when the previous 3 queue numbers before the queue number obtained by the patient has received service. Estimated turn time is obtained through this calculation (1)

$$
\text { Estimated Turn Time }=\frac{\text { total servicetime }}{\text { total served patients }}
$$

Patients who have registered can cancel the arrival via Telegram and SMS by sending the message "/batal: [medical record number]", if successful then the bot will reply with the message "Successful Cancellation". Patients who want to get queue data information can send the message "/get: medical record number" via Telegram and SMS. The bot will send patient data in the form of a queue number, medical record number, name, type of service, patient telephone, and the number of queues in front of the patient.

\section{B. System Interface}

The initial interface in the E-Queue Application based on Multi Channel Access Technology (MCA) can be seen in Fig. 4.

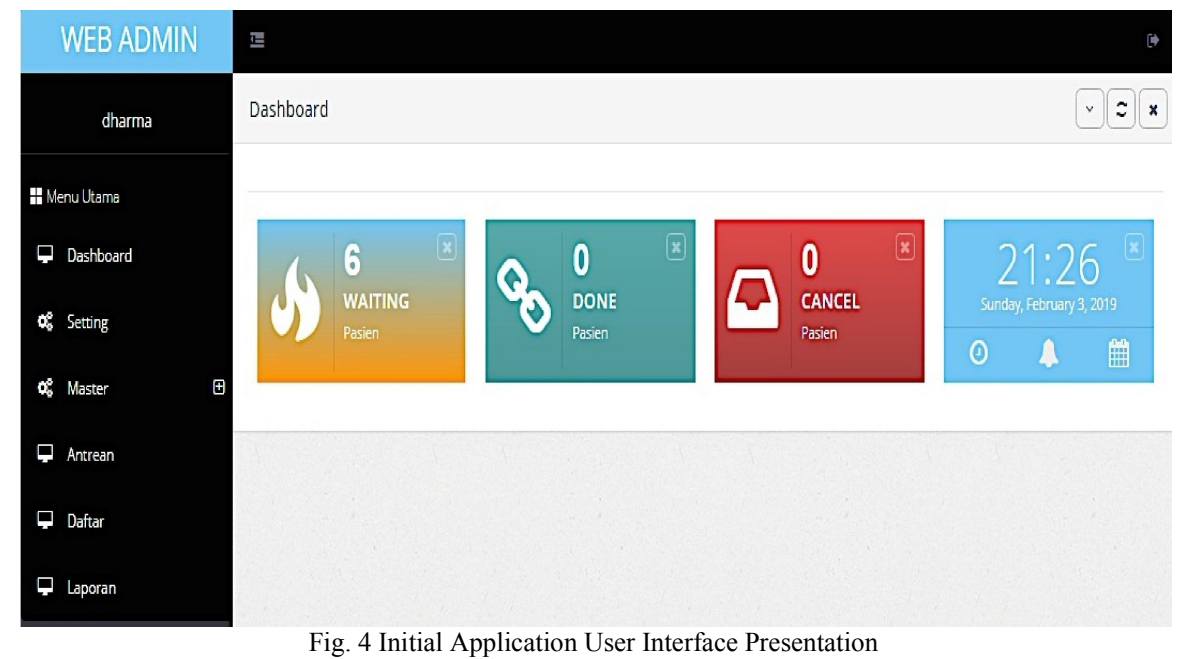

Fig. 4 shows the start page view of the application. The application's home page contains information about existing features in the E-Queue Application based on Multi Channel Access Technology (MCA), namely the Dashboard, Settings, Master Data, Queue, List and Report menus. The dashboard page can show the number of patients who are waiting, the number of patients cancelling arrivals, and the number of patients who have received services on that day.

\section{Quene Feature}

The queue feature in the E-Queue Application based on Multi Channel Access Technology (MCA) can be seen in Fig. 5. Fig.5 shows a queue feature page display from the E-Queue Application based on Multi Channel Access (MCA) Technology. The queue feature is used by the admin to manage registered queues. Admin will update the status when the patient has received service, is late to arrive, or cancel the visit. 


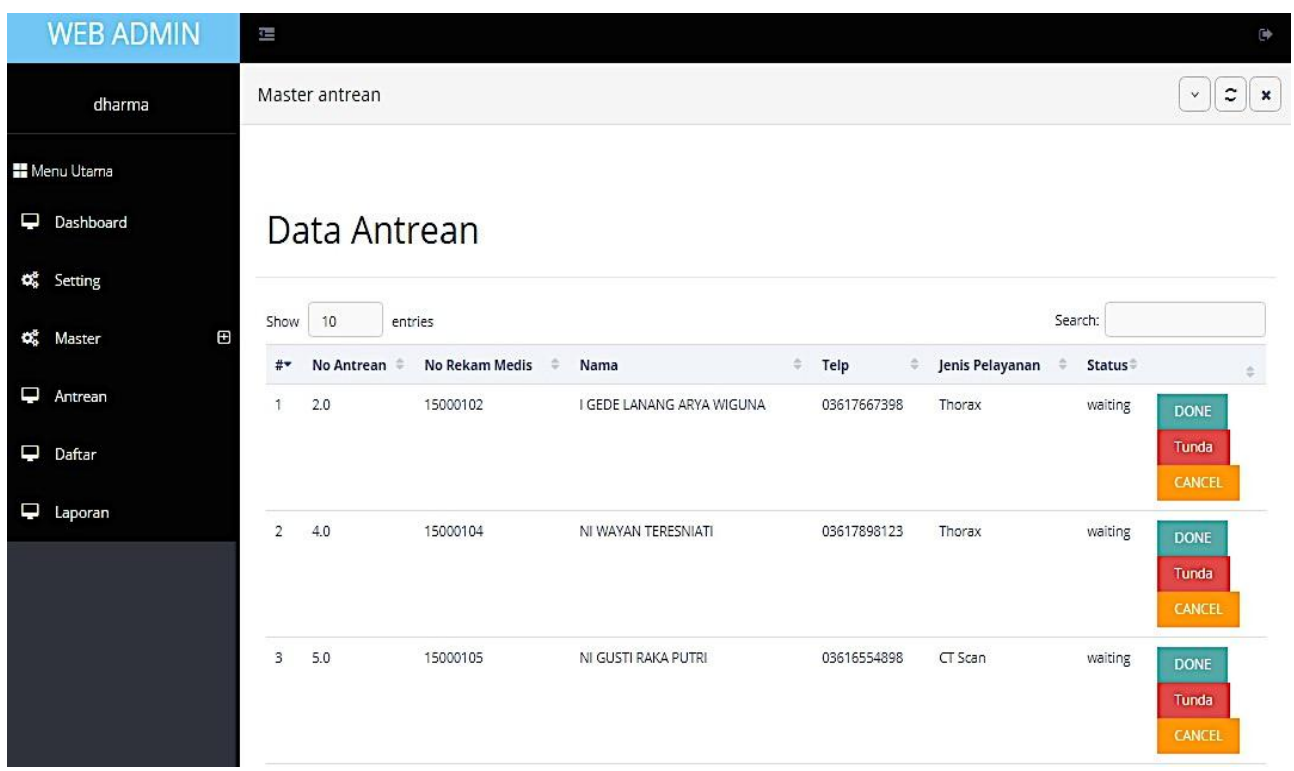

Fig. 5 Queue Feature

D. Telegram and SMS

Bots are computer programs that do certain jobs automatically. Bots are run by the application. The commands that are executed will be explained in Table 1.

TABLE 1

TELEGRAM AND SMS BOTS

\begin{tabular}{cc}
\hline Command & Function \\
\hline /daftar & Register at the Radiology Section of the hospital \\
/batal & Cancel the arrival at the Radiology Section of the Hospital \\
/get & Retrieve queue information. \\
\hline
\end{tabular}

Table 1 is a table that displays commands and functions found in Telegram and SMS Bots. Commands consist of /daftar, /batal, and /get. Telegram bots and SMS can also send notifications according to the queue that occurs. Telegram Bot Notifications and SMS will be explained in Table 2.

TABLE 2

NOTIFICATION TELEGRAM DAN SMS

\begin{tabular}{cr}
\hline Notification & Field \\
\hline Nearest Queue Notification & The current queue number is 2, the next 3 lines are your turn. Please come to the \\
Relay Notification & Radiology Section of Sanglah Hospital. Estimated turn of 150 minutes. \\
Cancellation Notification & You are late. Your queue is moved forward after number 8.
\end{tabular}

Table 2 lists and displays notifications from Telegram and SMS Bots. There is three types of notification. First type of notification, Nearest Queue Notification is sent to the 3 queue numbers before be served by healt services, giving patient suggest to come to the Radiology Section of Sanglah Hospital and informing the estimated turn time to be served in the form of the average service time. Second type of notification, Delay Notification is sent if the patient do not in the Radiology Section of Sanglah Hospital when he is called. This notification informs the new queue number and number of patients were backed up. Third type of notification, Cancellation Notification is obtained by the patient if the patient arrives late and the queue is delayed. This notification is sent to inform to the patient if he is delayed gets a turn and still hasn't arrived, the patient line will be cancelled.

\section{E. Interface Trials}

Trials will be conducted starting from registration through the Telegram application. Tests on the E-Queue Application based on Multi Channel Access Technology (MCA) are explained as follows. 


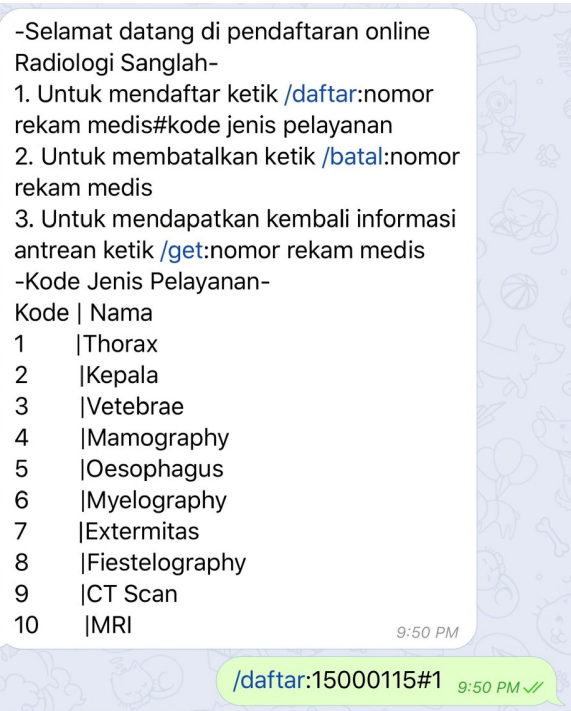

Fig. 6 Telegram Registration

Fig. 6 is the registration display through the Telegram application. Patients will get a message on how to register, cancel the arrival, and get information on the patient's queue number. Patients who have registered will get a reply in the form of queue data as shown in Fig. 7, and a notification when the queue obtained is close as shown in Fig. 8.

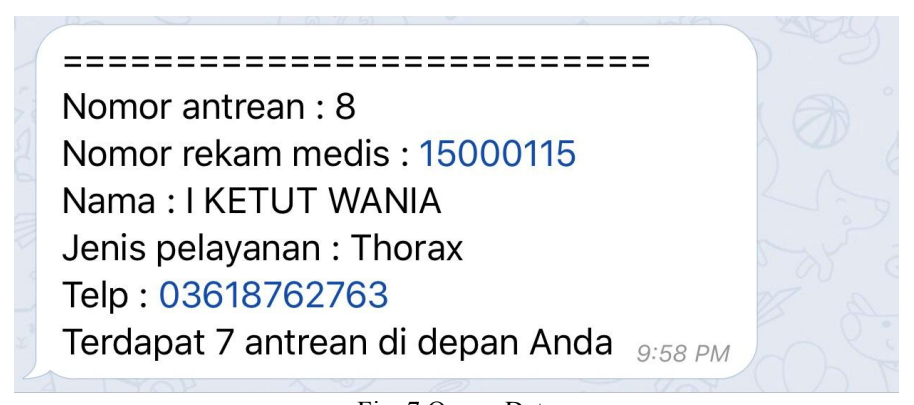

Fig. 7 Queue Data

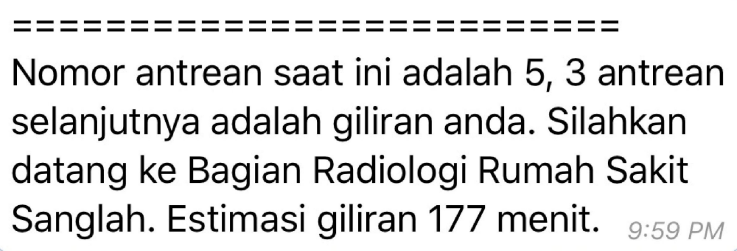

Fig. 8 Queue Notification

Fig. 7 is a display of queue data when the patient registers through the Telegram application. Queue data contains the queue number, medical record number, patient's name, type of service, patient's telephone number, and information on the number of lines in front of the patient. Bot's notification when the queue number obtained is near can be seen in Fig. 8. Patients will receive a notification to come to the Radiology Section of Sanglah Hospital when there are 3 queue numbers before the queue number that is obtained by the patient has received service.

\section{F. System Evaluation}

Evaluation is the last part of the system formation stage and is carried out to ensure the quality of a system. The results of this test are possible errors / bugs in the system so that it can be a correction for the future. 


\section{1) Normal Queues}

E-Queue Application based on Multi Channel Access (MCA) Technology can run well and there are no bugs even if the user registers simultaneously. The application can accommodate and respond according to the instructions given. The time it takes the application to respond and send notifications is 0.02 seconds.

2) Patient Arrives Late

Tests are carried out when a situation occurs in which one patient arrives late. E-Queue Application based on Multi Channel Access Technology (MCA) can overcome patient delay problems. Trials can be seen in Fig. 9 . Fig. 9 show the queue data that has been registered. The admin will press the "Snooze" button when there are patients who arrive late or not when called. Patients with line number 5 on behalf of "Ni NengahJuniarti" arrive late and will be tucked into the next 3 lines. The result when the admin presses the "Delay" button can be seen in Fig. 10.Patients on behalf of "Ni NengahJuniarti" who previously held line number 5, inserted into 3 lines then became after line number 8 which is 8.1 .

\begin{tabular}{|c|c|c|c|c|c|c|c|}
\hline & No Antrean & $n \neq$ No Rekam Medis & A Nama & Telp & Jenis Pelayanan & Status $f$ & \\
\hline & 4.0 & 15000104 & N WAYAN TERESNITI & 03617898123 & Thorax & watiting & DONE \\
\hline & 5.0 & 15000105 & N GUSTI RAKA PUTRI & 03616554898 & $\pi$ sean & watiting & DONE \\
\hline & 6.0 & 15000106 & N NENGAH JUNIARTII & 03616776545 & Thorax & wating & DONE \\
\hline \multicolumn{8}{|c|}{ Fig. 9 Patient Arrives Late } \\
\hline \multirow[t]{3}{*}{6.0} & & 15000106 & NI NENGAH JUNIARTI & 03616776545 & Thorax & wäting & DONE \\
\hline & & & & & & & Tunda \\
\hline & & & & & & & CANCEL \\
\hline \multirow[t]{3}{*}{7.0} & & 15000107 & KOMANG MAHARYANA & 03619008767 & Fiestelography & wäting & DONE \\
\hline & & & & & & & Tundá \\
\hline & & & & & & & CANCEL \\
\hline \multirow[t]{3}{*}{8.0} & & 15000108 & IMADE SUDIANTA & 03618473829 & Thorax & waiting & DONE \\
\hline & & & & & & & Tunda \\
\hline & & & & & & & CANCEL \\
\hline \multirow[t]{3}{*}{8.1} & & 15000105 & NI GUSTI RAKA PUTRI & 03616554898 & $\pi$ can & wating & DONE \\
\hline & & & & & & & Tunda \\
\hline & & & & & & & CANCEL \\
\hline
\end{tabular}

Fig. 10 Patient Arrives Late 


\section{3) Connection Lost}

Tests are carried out when the power goes out and the internet connection is lost. The E-Queue Application based on Multi Channel Access (MCA) Technology will not work because the supporting facilities in the form of the internet are not connected to the application, so the Bot cannot poll and the server cannot process data.

4) Phone Dies when Registering

The problem that occurs when a cellphone is used by a user to register dead. When this happens, users can still access the queue data that is registered on other cellphones by sending "/ get: medical record numbers" to the Telegram Bot or to the SMS gateway number. Access to queue data can be seen in Fig. 11. Fig. 11 is a response when the user accesses the queue data by sending "/ get: medical record number" to the SMS gateway number. Users can access again with cellphones or other gadgets when the handphone used registers to death, so users do not need to worry if the queue registered is missing or invalid.

\section{Text Message}

\section{/get: 15000108}

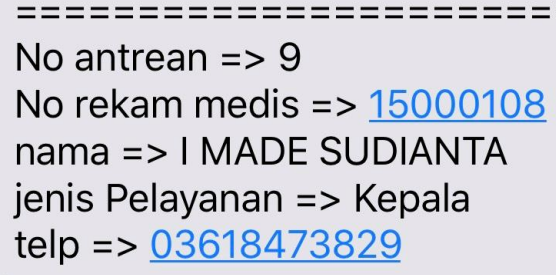

Fig. 11 Get Queue Data

\section{DISCUSSION}

Previous research [4] had developed a website-based system that allows users to monitor their queue status from the website service application. This system is designed to offer options for people who are waiting for services as they can go anywhere when they are in line. This queue system can only be accessed through the website. Users who do not have supporting devices such as smartphones or laptops cannot access it, while in this study with the application of Multi-Channel Access (MCA) technology, users have the option of registering, making it easier for users to register via Telegram or SMS applications. Users also get a notification when the queue number that is obtained is near, so the user does not wait too long in the waiting room. Other research such as "Android-based Queue Notification System" [6] developed a system that can provide information about ongoing queues and facilities for ordering queue numbers to someone from anywhere via a smartphone with the Android operating system. It was well made, but is still fixated on Android, while in this study the system was made with Multi Channel Access (MCA) technology with Telegram and SMS gateway that allows users who have smartphones and IOS operating systems and Android to register and use this system. SMS gateway is also provided in this application to anticipate patients who have not used a smartphone.

\section{CONCLUSIONS}

As conclusion, Untethering the Queue based on Multi Channel Access (MCA) Technology can be developed. This system facilitates patients for joint the queue in the hospital virtually and kept their queue number online via the Telegram and SMS application. Notification features allows patients to queue anywhere and only come to the Radiology Section of Sanglah Hospital if the application notifies the patients. The application of the Untethering the Queue based on Multi Channel Access Technology (MCA) is expected to be tested in the real environment, hence it can facilitate patients in queuing at the Radiology Section of Sanglah Hospital.

\section{REFERENCES}

[1] S. N. Rochmawati, F. Nurdiyansyah, and U. W. Malang, "Aplikasi Penentuan Nomor Urut Antrian Rumah Sakit Melalui Sms Gateway," Jurnal of Information Technology and Computer Science (JOINTECS), vol. 1, no. 2, pp. 1-4, 2017.

[2] M. Ngorsed and P. Suesaowaluk, "Hospital Servoice Queue Managament System with Wireless Approach," eJournal of Interdisciplinary Research, pp. 550-559, 2015. 
[3] R. A. Mahessya, R. Pramana, Gushelmi, and Ikhsan, "Penerapan Queueing Theory Pada Sistem Antrian," Jurnal Sains dan informatika, pp. 9-16, 2017.

[4] R. A. Zulfikar and A. A. Supianto, "Rancang Bangun Aplikasi Antrian Poliklinik Berbasis Mobile," J. Teknol. Inf. dan Ilmu Komput., no. October, 2018.

[5] J. Risanto and Z. Bahri, "Aplikasi Sistem Antrian berbasis Android," Information System And Informatics Engineering, vol. 1, no. 1, pp. 1-68, 2017.

[6] W. Musu, "Perancangan Sistem Informasi Antrian Berbasis SMS Getway Pada Klinik Herona Medical Pare Pare," pp. 68-72, 2015.

[7] E. Lumba, "Sistem Antrian untuk Mempermudah Pelayanan Pasien Rawat Jalan Pada Puskesmas XYZ," I-STATEMENT: Information System and Technology Management, vol. 1, no. 1, pp. 41-50, 2015.

[8] R. Sunarya, M. Aritonang, and Helmi, “Analisis Penerapan Sistem Antrian Model m/m/s pada PT . Bank Negara Indonesia (Persero) Tbk . Kantor Cabang Pontianak ( Studi kasus pada BNI Sultan Abdurrahman )," Buletin Ilmiah Mat, Stat, dan Terapannya (Bimaster), vol. 04 , no. 2, pp. 111-118, 2015.

[9] D. C. Silaban et al., “Analisis Kinerja Sistem Antrian M / M / 1,” vol. 7, no. 3, pp. 165-170, 2014.

[10] Mr.M.Vijayakumar, D. V. Karthikeyani, and M. M. Omar, "Implementation of Queuing Algorithm in Multipath Dynamic routing architecture for effective and secured data transfer in VoIP," International Journal of Engineering Trends and Technology, vol. 4, no. April, pp. 1226-1230, 2013.

[11] G. Arun, K \& Nayagam, "Building Applications with Social Networking API's,” vol. 2075, pp. 2070-2075, 2014.

[12] K. Darmaastawan, I. M. Sukarsa, and P. W. Buana, "LINE Messenger as a Transport Layer to Distribute Messages to Partner Instant Messaging," Modern Education and Computer Science, no. March, pp. 1-9, 2019.

[13] D. Agung, K. Arimbawa, I. K. Gede, D. Putra, and I. M. Sukarsa, "Library System Using Radio Frequency Identification ( RFID ) and Telegram Bot API,” Lontar Komputer, vol. 9, no. 1, pp. 40-51, 2018.

[14] Ahmad Hanafi, M. Sukarsa, and A. Cahyawan, "Pertukaran Data Antar Database dengan Menggunakan Teknologi API," Lontar Komputer, vol. 8, 2017.

[15] B. Wahyudi, I. M. Sukarsa, and P. Wira Buana, "Rancang Bangun Tracking Mobil Patroli Berbasis," E-Journal SPEKTRUM, vol. 4, no. 1, pp. $49-53,2017$.

[16] Suardinata and A. Lubis, "Pembuatan Sistem SMS Gateway Untuk Kelancaran Tagihan Pelanggan Di PT PLN Cabang Padang,” Jurnal Edik Informatika, vol. 2, no. 1, pp. 36-44, 2015.

[17] Mesterjon, "Street Light Monitoring Application Based On SMS Gateway Mesterjon,” Int. J. Sci. Res. Publ., vol. 6, no. 11, pp. 536$539,2016$.

[18] I. R. Purba, I. K. A. Purnawan, and I. G. M. A. Sasmita, "Sistem Antrean Pelayanan Medis Praktik Dokter Bersama berbasi Web," Lontar Komputer, vol. 4, no. 3, pp. 248-258, 2016.

[19] R. C. Dinatha, I. M. Sukarsa, A. A. K. Agung, and Cahyawan, "Data Exchange Service using Google Drive API," International Journal of Computer Applications, vol. 154, no. 7, pp. 12-16, 2016. 